C. E. BLANK ET AL. CHROMOSOME MOSAICISM IN A HERMAPHRODITE

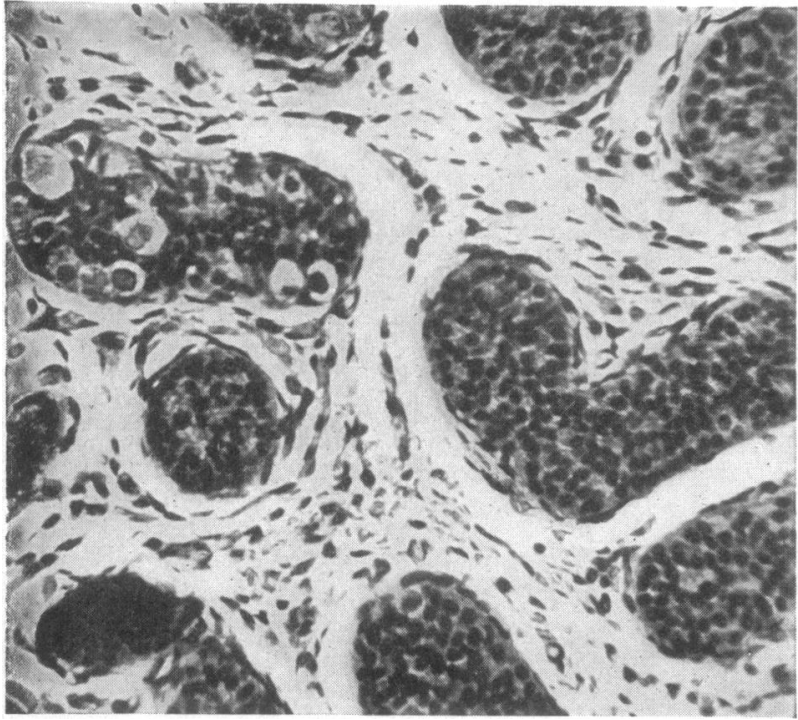

FIG. 1.-Biopsy of right gonad taken at 10 weeks, showing essentially normal testicular tissue. $(\times 205$.

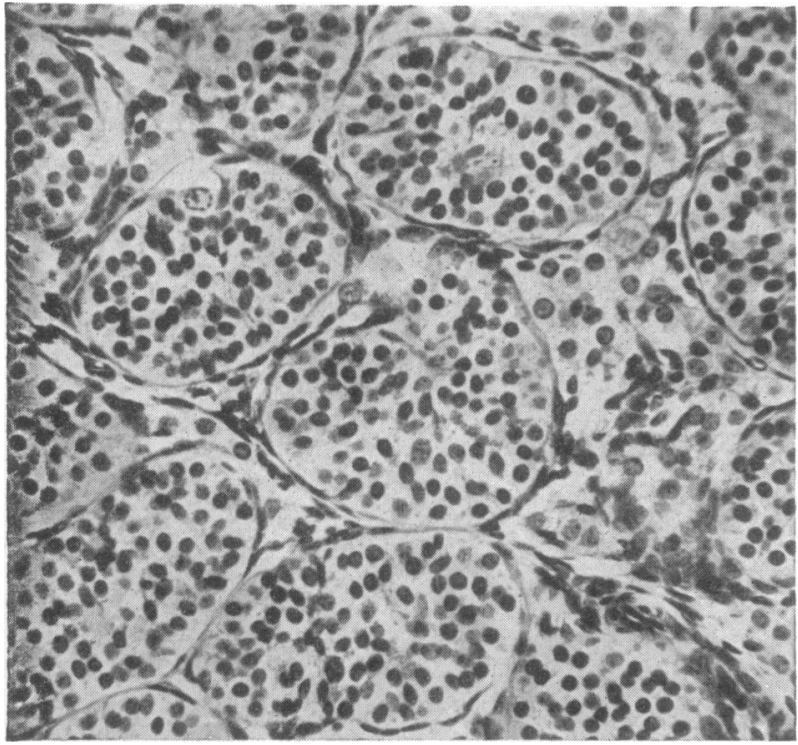

Fig. 2.-Right gonad removed at 14 weeks, showing essentially normal testicular tissue. $(\times 205$.

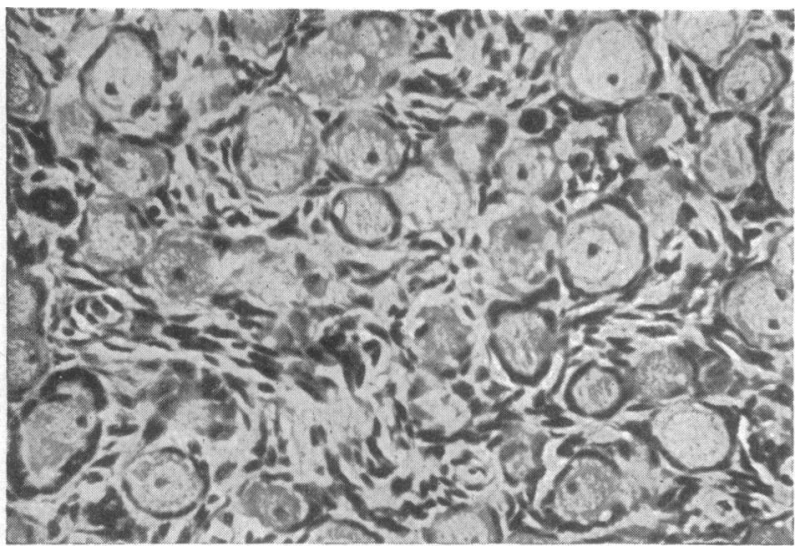

FIG. 3.-Section from left gonad. $(\times 205$.
J. FORSHAW AND E. H. MOORHOUSE: AMYLOIDOSIS AND CHRONIC ULCERATIVE COLITIS

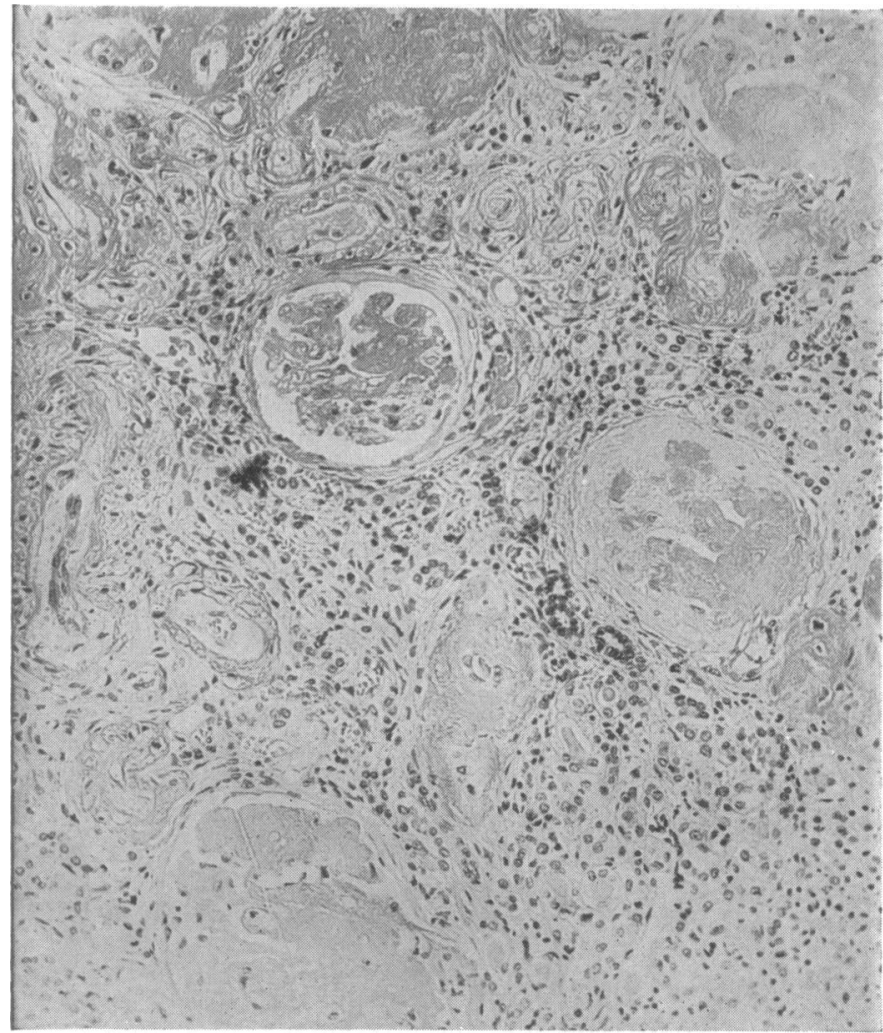

Fig. 1.-Case 1. Section of cortex of kidney showing amyloidosis of glomeruli and interstitial fibrosis with round-cell infiltration. (Congo red. $\times 115$.)

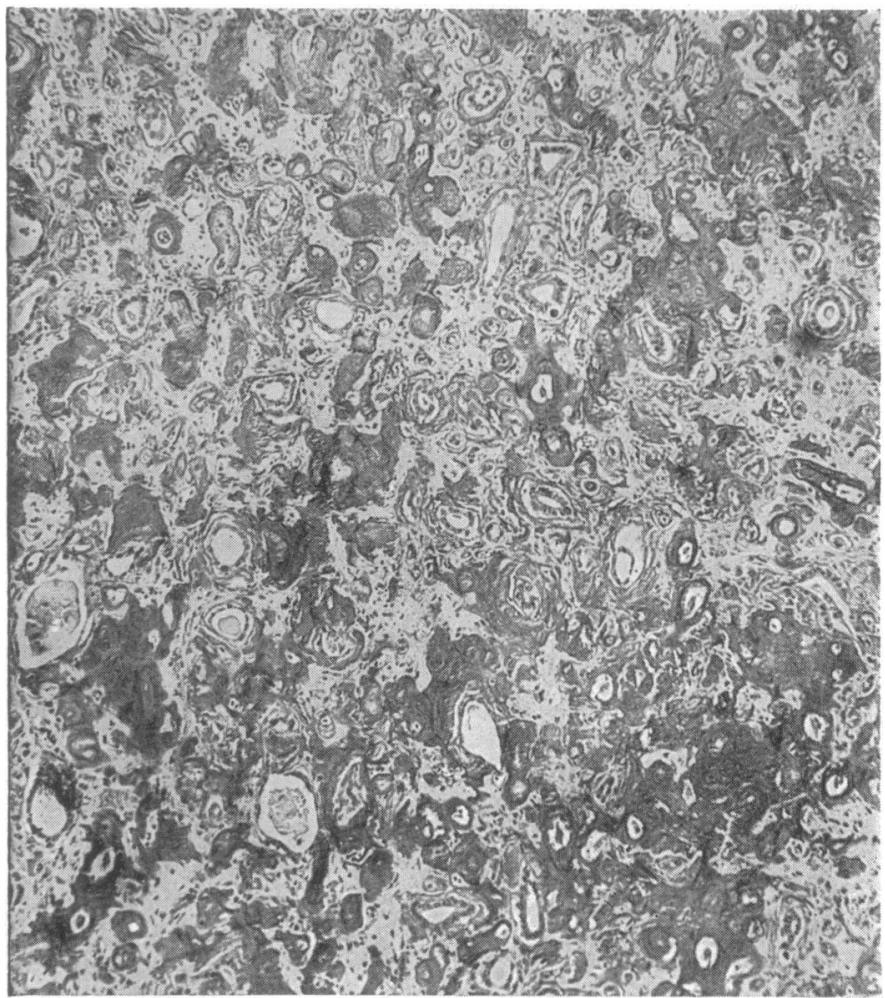

Fig. 2.-Case 1. Section of medulla of kidney, showing tubular atrophy and tubular and interstitial amyloidosis. (Congo red. $\times 115$.) 


\title{
Amyloidosis Secondary to Chronic Ulcerative Colitis
}

\author{
J. W. B. FORSHAW,* M.A., M.D., M.R.C.P. ; E. H. MOORHOUSE, † M.R.C.S., L.R.C.P.
}

[With Special Plate]

Brit. med. F., 1964, 2, 94-95

Amyloidosis is a rare complication of chronic ulcerative colitis, and is seldom included in reviews of the disease. For instance, Edwards and Truelove (1964) do not mention amyloid disease in a list of 554 systemic complications occurring in 624 patients with ulcerative colitis. Only 10 cases have been described in detail, and seven others have been mentioned (Targgart, Trump, Lagunoff, and Eschbach, 1963). Fifteen of these cases were reported from America and only one from Britain (Heptinstall and Joekes, 1960). We describe here two cases of chronic ulcerative colitis, in which death was caused by renal amyloidosis.

\section{Case 1}

A woman aged 35 was referred to the haematology clinic at Sefton General Hospital in November 1962 with a complaint of lassitude for two months. She had had occasional attacks of mild diarrhoea for six years, the last attack having occurred two months previously. Significant past illnesses were erythema nodosum in 1956, anaemia treated by blood transfusions in 1957, and excision of an ischio-rectal abscess in 1958.

On examination she was pale, but there were no other abnormal signs. The haemoglobin level was $4.9 \mathrm{~g} . / 100 \mathrm{ml}$. and the blood film showed marked hypochromia of the red cells. The urine contained a moderate amount of albumin. The appearance of a barium-meal $x$-ray film indicated extensive ulcerative colitis. She would not enter hospital for further investigation, and as diarrhoea was not occurring at the time she received no treatment other than oral and parenteral iron. During the next two months the lassitude improved and the haemoglobin level rose to $9.3 \mathrm{~g}$.

In February 1963 a further attack of diarrhoea developed, accompanied by pain in the right iliac fossa, and she was admitted to hospital. On examination the only abnormal sign was tenderness in the right iliac fossa. The stools were watery and contained streaks of blood.

\section{Investigations}

Haemoglobin, 8.9 g.; erythrocyte sedimentation rate, $54 \mathrm{~mm}$. in one hour. The blood film showed slight hypochromia of the red cells. The urine contained a moderate amount of albumin with numerous casts and leucocytes, and culture produced a growth of Escherichia coli. No pathogenic organisms were obtained on culture of the stools. Serum urea was $130 \mathrm{mg}$., sodium $325 \mathrm{mg}$., potassium $18.7 \mathrm{mg}$., albumin $4.2 \mathrm{~g}$., globulin $2.9 \mathrm{~g}$., alkali reserve $26 \mathrm{ml} . \mathrm{CO}_{2}$, iron $16 \mu \mathrm{g}$., total iron-binding capacity $375 \mu \mathrm{g} . / 100$ $\mathrm{ml}$ Serum vitamin $\mathrm{B}_{12}$ was $190 \mu \mu \mathrm{g} . / \mathrm{ml}$. A barium-enema $x$-ray examination showed that the colon was very contracted, with changes of severe ulcerative colitis in the transverse and descending colon. The view at sigmoidoscopy was obscured by copious fluid faeces, but the rectal mucosa bled easily. Cystoscopy and retrograde pyelograms ware normal.

The ulcerative colitis was treated with hydrocortisone hemisuccinate enemas twice daily for 10 days and oral prednisone, which was continued up to the time of her death. The diarrhoea ceased within a few days and there were no furthcr attacks. The urine was sterilized temporarily by successive treatment with nitrofurantoin, ampicillin, and sulphafurazole. The acidosis was treated with $6 \mathrm{~g}$. of sodium

* Consultant Physician, Sefton General Hospital, Liverpool.

† Pathologist, Sef on Ceneral Hospital, Liverpool. bicarbonate daily and the serum alkali reserve rose to $52 \mathrm{ml}$. $\mathrm{CO}_{2}$ $100 \mathrm{ml}$. After six weeks in hospital she returned home on treatment with prednisone $5 \mathrm{mg}$. daily and iron. At this time the serum urea had risen to $280 \mathrm{mg}$. and the haemoglobin level was $7.3 \mathrm{~g}$.

Two months later she was readmitted to hospital with severe cramp-like pains in the hands and feet. The haemoglobin was 6.8 g., serum urea $520 \mathrm{mg}$., potassium $17.6 \mathrm{mg}$., calcium $8.2 \mathrm{mg}$., an alkali reserve $20 \mathrm{ml}$. $\mathrm{CO}_{2} / 100 \mathrm{ml}$. She improved temporarily after correction of the acidosis, but her condition then steadily deteriorated and she died in September 1963.

\section{Post-mortem Examination}

The lungs were oedematous and there were bilateral pleural effusions. The left ventricle of the heart was enlarged and there was a fibrinous pericarditis with an effusion. The colon, distal to the hepatic flexure, was markedly contracted and the lumen was narrowed. Small islands of colonic mucosa were present, but microscopy showed that the mucosa was largely replaced by fibrous tissue and chronic inflammatory granulation tissue. The kidneys were contracted and granular, and the pelves appeared normal. Microscopical examination (Special Plate, Figs. 1 and 2) showed extensive amyloid infiltration of the glomeruli, tubules, and arterioles. Marked tubular atrophy and interstitial fibrosis with cellular infiltration were present. The bladder showed no evidence of cystitis. The spleen was enlarged and firm, and the liver, pancreas, and adrenals appeared normal. Amyloidosis of these organs was not suspected at the time of the necropsy, and no tissue was taken for histological examination.

\section{Case 2}

A woman aged 41 was referred to the renal unit at Sefton General Hospital in July 1963 on account of the recent development of oliguria. Attacks of diarrhoca had begun in 1946, and in the following year she developed a recto-vaginal fistula. Investigations at this time showed that the inflammation was limited to the rectum, and in 1948 a colostomy of the distal descending colon was performed. The recto-vaginal fistula slowly healed, but she continued to have an intermittent purulent discharge from the anus. Resection of the rectum was considered subsequently, but in view of her good general health it was decided not to proceed with the operation.

In April 1963 she developed diarrhoea from the colostomy, and in July the diarrhoea became very severe. She was admitted to another hospital, where it was observed that she had passed only $400 \mathrm{ml}$. of urine during a period of three days and the serum urea was $250 \mathrm{mg}$. $/ 100 \mathrm{ml}$. She was then transferred to Sefton General Hospital.

On examination her general condition was very poor and there was evidence of considerable loss of weight. The blood-pressure was $95 / 65$, and there was tenderness over the lower abdomen. The haemoglobin was $12.8 \mathrm{~g} . / 100 \mathrm{ml}$; leucocytes $34,000 / \mathrm{c} . \mathrm{mm}$. (neutrophils $95 \%$ ); and the stained blood film showed a number of burr cells. The serum urea was $230 \mathrm{mg}$., sodium $328 \mathrm{mg}$.; potassium $18.8 \mathrm{mg}$., and alkali reserve $18.5 \mathrm{ml} . \mathrm{CO}_{2} / 100 \mathrm{ml}$. The urine contained a moderate amount of albumin and numerous leuco zytes and red blood cells; culture produced a growth of Proteus vulgaris. She was treated with parenteral steroids and intravenous $5 \%$ dextrose and 1/6 M sodium lactate solutions. After receiving 2 litres of fluid during a period of 24 hours she excreted only $30 \mathrm{ml}$. of 
urine and the serum urea rose to $450 \mathrm{mg} . / 100 \mathrm{ml}$. Haemodialysis was then carried out and the serum urea fell to $180 \mathrm{mg}$. However, her general condition continued to deteriorate and next day she died.

\section{Post-mortem Examination}

The appearance of the heart was normal and there was patchy consolidation in both lungs. The whole length of the colon above the colostomy showed the macroscopic and histological changes of severe ulcerative colitis. The rectum and the small length of colon below the colostomy consisted of a fibrosed tube without any lumen. The pancreas, adrenals, and bladder appeared normal. The liver, spleen, and kidneys felt very firm, but were normal in size. Histological examination of the kidneys and spleen showed widespread amyloid infiltration in both these organs and the renal amyloidosis involved the glomeruli, tubules, and arterioles. Sections of the liver were not taken.

\section{Comment}

Although amyloidosis has rarely been observed in ulcerative colitis, it should always be considered in those patients with signs of renal disease. Renal amyloidosis was present in all the 12 cases that have been reported in detail, and was responsible for death in 10 of these. The nephrotic syndrome was present in eight patients, six of whom were also uraemic. The two patients described here were the only ones with uraemia who did not have signs of nephrosis.

Factors which appear to lead to the development of amyloidosis are a long history of ulcerative colitis, perirectal suppuration, and delay in performing a colectomy when medical treatment has failed. Eight of the 12 patients had perirectal abscesses or fistulae, and in 10 patients the diagnosis of ulcerative colitis was made more than four years before that of amyloid disease. Either perirectal suppuration or a long history of ulcerative colitis was present in all the patients.

Colectomy had not been carried out in 11 patients, and the other patient had had a subtotal colectomy two years before her death. The prevention of amyloidosis is therefore a further indication for early colectomy in patients with persistent active colitis ; for, once renal amyloidosis has developed, subsequent successful treatment of the ulcerative colitis may not prevent the development of renal failure.

\section{Summary}

Two cases of chronic ulcerative colitis are described in which death was caused by renal amyloidosis. Both patients were uraemic and neither had signs of nephrosis. A review of these two cases, together with the 10 others described previously, suggests that important aetiological factors are perirectal suppuration, a long history of ulcerative colitis, and delay in performing a colectomy when medical treatment has failed.

We wish to thank Mr. Eric Edwards and Dr. E. Mavis McConnell for permission to publish the clinical and pathological details respectively of Case 2 .

\section{REFERENCES}

Edwards, F. C., and Truelove, S. C. (1964). Gut, 5, 1.

Heptinstall, R. H., and Joekes, A. M. (1960). Ann. rheum Dis., 19, 126. Targgart, W. H., Trump, B. F., Lagunoff, D., and Eschbach, J. (1963). Gastroenterology, 44, 335.

\title{
Duration of Stay in Hospital for Normal Maternity Care
}

\author{
E. D. ACHESON,* M.A., D.M., M.R.C.P. ; M. S. FELDSTEIN, $†$ A.B., B.LITT.
}

\section{Brit. med. F., 1964, 2, 95-99}

In Britain one of the main issues in hospital planning today concerns the number of maternity beds that should be provided. This number depends upon three factors: (1) the number of births per year; (2) the proportion of deliveries taking place in hospital ; (3) the mean length of stay. In 1961, $66 \%$ of British births occurred in hospital ; in the future, according to the recommendations of the Cranbrook Committee, this proportion should be stabilized at $70 \%$. However, it seems at least as likely that it will continue to rise towards the very high figure which is current in the United States, Australia, and Sweden. If this is so, and the prevailing birth-rate is maintained, the extent to which new building is required will depend directly upon the duration of stay in hospital.

In a recent article Sir George Godber (1963) has called for further information concerning factors which determine duration of stay in maternity beds and for follow-up information to determine the effects of longer or shorter stays in hospital on the health of mother and baby. In the present paper, which is the first of a series planned to study this topic, an analysis will be made of the variation in the duration of stay for normal

\footnotetext{
* First Assistant, Nuffield Department of Medicine, The Radcliffe Infirmary, Oxiord.

† U.S. Public Health Service Research Fellow in Health Care Economics, Nuffield College, Oxford.
}

maternity care, and, in particular, the extent to which this variation is due to differences in the behaviour of the doctors in charge rather than to differences in the medical or social needs of their patients.

\section{Material}

The studies reported here are based on data routinely collected by the Oxford Record Linkage Study (ORLS); (Acheson, 1964 ; Acheson and Evans, 1964). This project involves the collection and integration in a single central file of information concerning every delivery (whether at home or in hospital), discharge from hospital, and death in the population of Oxford County Borough, Oxfordshire (except Henley), and part of Berkshire.

Of 4,435 hospital deliveries in the ORLS area in 1962, there were 2,142 normal deliveries (I.S.C. 660.0), in which no complication of pregnancy, delivery, or the puerperium had been recorded, and which resulted in the birth and subsequent discharge of a living baby, accompanied by its mother. ${ }^{1}$ Deliveries

\footnotetext{
The reduction from 4,433 to 2,142 was as follows: 2,163 deliveries were omitted because of complications of pregnancy, delivery, or puerperium; 101 were omitted because mother and baby were not discharged home together; 27 of the remaining deliveries were omitted because they resulied in muliple births.
} 